\title{
Recent trends in disease occurrence in the non-traditional rubber-growing areas of Sri Lanka
}

\author{
M K R Silva*, T H P S Fernando*, R L C Wijesundara**, C N Nanayakkara** \\ and B I Tennakoon* \\ * Rubber Research Institute of Sri Lanka, Dartonfield, Agalawatta, Sri Lanka \\ ** Department of Plant Sciences, University of Colombo, Colombo, Sri Lanka
}

\begin{abstract}
As the rubber industry is being extended to non-traditional areas in Uva, Northern and Eastern provinces in Sri Lanka, it was important to extend the crop protection arm to those areas also. The disease profile recorded in those areas for a period of three years was studied. The symptomatology of the major diseases and the diversity of the Sri Lankan populations of the pathogens causing major diseases were also studied. Furthermore, the alternative hosts of the pathogens of the major diseases were also looked for. With the observations made, it could be concluded that, during the study period, brown root disease was the malady with the highest incidence in the non-traditional rubber-growing areas of Sri Lanka. Encrustation of sand and stones on the root surface could be identified as the characteristic diagnostic symptom of the disease. The different isolates of Phellinus noxius showed variations in colony morphology. With the contextual observations of the reported incidences, drier soil conditions, poor land preparation and association with the forest-associated tree species were suggested to be the major reasons for the higher incidence of brown root disease in the studied areas. White root disease was also recorded to a lesser extent. Corynespora leaf fall disease was found to be the foliar disease with the highest incidence. Cow pea (Vigna unguiculata) and soy bean (Glycine max) were recorded to be two alternative hosts of Corynespora-causing fungus.
\end{abstract}

Key words: disease profile, Hevea brasiliensis, non-traditional rubber-growing areas

\section{Introduction}

Due to the fact that there is no more land available in the traditional rubbergrowing areas of Sri Lanka, the rubber industry is being extended to nontraditional rubber growing areas in Uva, Northern and Eastern provinces where land and labour are non-limiting factors.
This was carried out during the first decade of the new millennium and most of these clearings are now in the immature phase or at the beginning of tapping. The newly established lands are mostly cleared natural forests and rubber is being the first plantation crop. As these non-traditional areas include 
M K R Silva et al.

parts of Low/Mid Country Intermediate and Dry Zones, the crop may face different agro-climatic conditions. Moreover, in those areas, the environmental factors such as the rain fall pattern, soil characteristics, and the natural flora and fauna are different from those of the traditional rubbergrowing areas of Sri Lanka. The management practices adopted and the cropping systems are also dissimilar to that of wet zone. These altered conditions not only influence the crop growth and development, but also affect the host-pathogen interactions, it was expected that the natural balance between the crops and the pathogens may have been disturbed leading to novel disease outbreaks.

This study was carried out to find out the disease profile recorded in the nontraditional rubber-growing areas of Sri Lanka; to identify the symptomatology of the major diseases and to study the diversity of the Sri Lankan populations of the pathogens causing diseases with high prevalence; identification of the alternative hosts of the pathogens of the major diseases.

\section{Materials and Methods \\ Surveying of the diseases}

The reported disease incidences from non-traditional areas in Uva province to the Rubber Research Institute of Sri Lanka between the period from mid2013 to mid-2016 was used as the sample of study. A structured questionnaire was used to collect the background information of each disease incidence.

\section{Collection and maintenance of the pathogen isolates}

Disease samples were collected from $H$. brasiliensis and other host species. Isolations were made on artificial media (Malt Extract Agar or Potato Dextrose Agar) from symptomatic roots/leaves/ bark portions after surface sterilization in $70 \%$ ethyl alcohol for 2 minutes. Pure cultures were obtained from hyphal tip isolations executed through microscopic observations. The cultures were maintained in the respective media at room temperature $\left(\mathrm{RT}, 28 \pm 2{ }^{\circ} \mathrm{C}\right)$. Four day old fungal cultures were used to study culture characteristics of inoculation. Description sheet of Commonwealth Mycological Institute (CMI) were used as a guide to identify the isolated fungi.

\section{Studies on the diversity of the pathogens and symptomatology of the diseases}

The isolates of the pathogens with highest incidence were used in the diversity study. They were grown on artificial media at RT in the dark for four days. Mycelial plugs of $9 \mathrm{~mm}$ diameter were removed with a sterile cork borer from the leading edges of the fungal colonies, and one such plug was placed in the center of each $90 \mathrm{~mm}$ Petri dish containing the medium.

The coloration, fluffiness and the density of the cultures as the culture characteristics were recorded after four days of inoculation. Ranks from 0-5 were given for the brownish colouration developed in the culture, as the rank zero and five being the lowest and highest colourations of the cultures 
respectively. The fluffiness was ranked from 1-4 as the rank one and four being the lowest and highest fluffiness respectively. The density was ranked from 1-3 as the rank one and three being the lowest and highest densities of the cultures respectively. Five replicates were used in all experiments.

The scores recorded based on the coloration, fluffiness and the density of the cultures for different isolates were analyzed employing Wilcoxon Rank Sum Test (WRST). Subsequently, the mean scores obtained through the WRST were used to group the isolates employing agglomerative hierarchical approach in cluster analysis as it is the most widely used method compared to divisive method (Rencher, 2002). The statistical software, Genstat ver.16 was used in the data analysis.

In the root diseases, the signs and the symptoms on the collar and the root systems were studied and in foliar disease incidences, the disease symptoms of the leaves were recorded.

\section{Studies on the alternative hosts}

In order to identify the possible alternative host species of the diseasescausing pathogens of rubber, the presence of live and dead non-rubber species in the vicinity of the diseased rubber trees were investigated. In each of the root disease incidences, the firstly-diseased rubber tree was traced and the root system of the tree was exposed as to find out the association of the roots of the neighboring trees with the respective tree. The signs and the symptoms of both the rubber tree as well as the associated tree were recorded.

In the case of foliar diseases, plants around the diseased rubber tree having foliar disease symptoms were selected to be tested for the existence of the pathogens.

\section{Results and Discussions \\ Disease profile recorded in the non- traditional areas}

As expected, the disease profile recorded was different from that of the traditional areas, hence the white root disease: which is recorded in the highest incidence in the traditional rubbergrowing areas was reported in a lesser rate. The major disease problems which were reported in a higher occurrence are described below.

\section{a) Brown root disease}

In 39 of the maladies, the signs and symptoms shown by the trees resembled those of the brown root disease. When observed under the microscope, as per the CMI descriptions, all the isolates resembled the microscopic characters of the Phellinus noxius, the causative fungus of the brown root disease of rubber. All the cultures grown in the laboratory showed distinctive raised brown and white plaques (patches) and produced arthrospores, which are asexual spores formed by the division of special hyphal segments.

This was the highest percentage of the maladies in non-traditional rubbergrowing areas and interestingly brown root disease is a condition which is less frequently reported from traditional 
rubber growing areas. This disease is distributed in tropical and sub-tropical regions of Asia, Central America, Africa and Oceania (Larsen and CobbPoulle. 1990; CABI/EPPO, 1997; Chang and Yang 1998; Ann et al., 2002). It was first recorded on Hevea in Ceylon in 1905 (Petch, 1911). Murray in year 1930 stated that, it is one of the commonest root diseases of Hevea in Ceylon (Murray, 1930). However, when the past few decades are concerned, the occurrence of brown root disease was controversial with the historical declaration. It was observed that the

disease was less-frequently reported and the reported incidences were confined to limited areas during the latter part of the $20^{\text {th }}$ century.

Diversity of the population of Phellinus noxius

The different isolates of Phellinus noxius showed variations in colony morphology (Fig. 1).

The coloration, density and the fluffiness in the culture figure showed variations and visible clusters could be obtained with all three characters (Fig. 2).

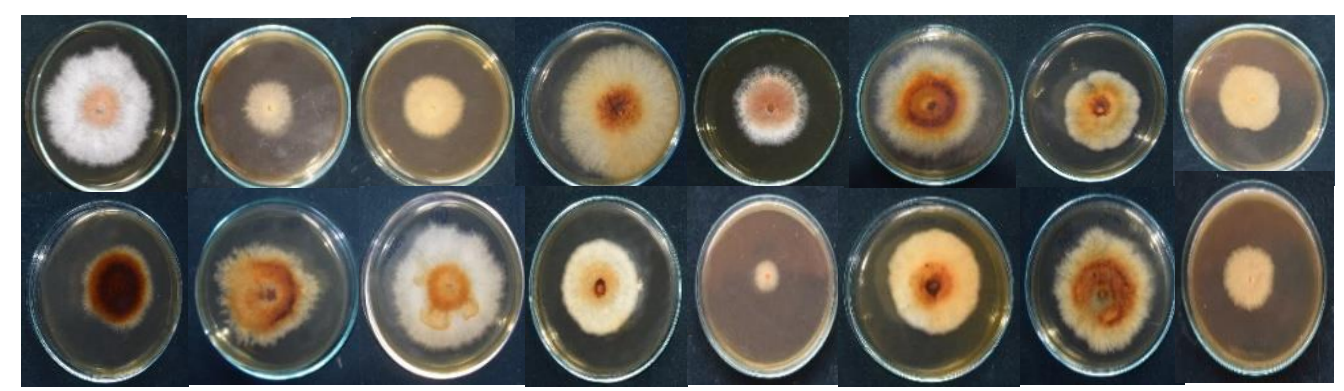

Fig. 1. Variability in cultural morphology of Phellinus noxius (after 3 days of growth under dark conditions)

a

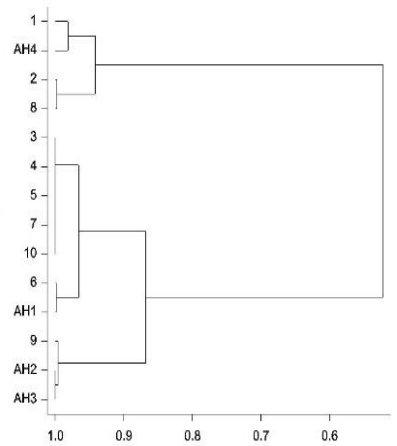

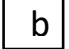

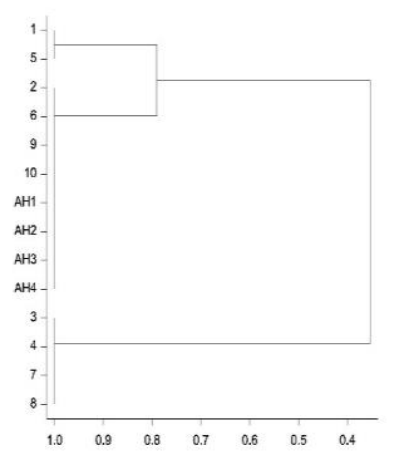

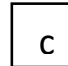

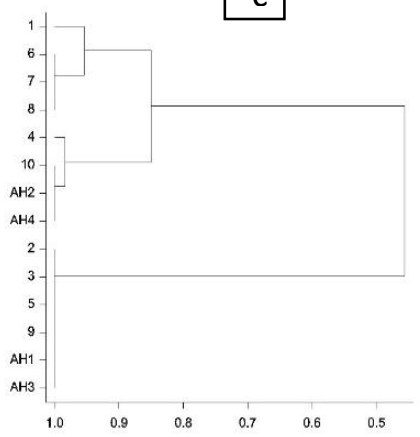

Fig. 2. Dendrograms showing the clustering of the isolates based on the a. colouration, b. density and c. fluffiness 
According to the mean score values, isolates showed a variability in all three colony characters: colouration, density and the fluffiness. Two groups were prominent in clustograms obtained for the characters. However, the clusters formed based on the three colony characters did not show a clear similarity. Moreover, the $P$. noxius isolates obtained from the other species have not shown a significant genetic distance among the $P$. noxius isolates from rubber.

\section{Signs and symptoms of the disease}

The aboveground symptoms of brown root disease were more or less similar to those caused by white root disease as symptoms are caused by hindrance of uptake and transport of water and nutrients from the soil. Slow plant growth, yellowing and wilting of leaves, defoliation and branch dieback were the major above ground symptoms (Figs. 3a $\& 3 b)$. However, time duration between the exhibition of the initial foliar symptoms and the death of the tree was much lesser than in the case of white root disease.

Roots infected with $P$. noxius initially exhibited a brown discoloration of the wood just beneath the bark (Fig. 3c). Tawny brown gummy rhizomorphs were firmly fixed to the outer bark surface with an encrustation of sand and stones on the root surface (Fig. 3d). This could be identified as the characteristic diagnostic symptom of the disease. The inner bark was covered with a white to brownish mycelial mat. The dead wood later become white, dry, and honey- combed (Fig. 3e). Occasionally, bracket like fructifications were observed on the basal trunks of diseased trees. The fructification was a dark brown hard bracket, dark grey on the underside. (Fig. $3 \mathrm{f} \mathrm{\&} \mathrm{3g).} \mathrm{In} \mathrm{addition} \mathrm{to} \mathrm{these} \mathrm{signs}$ and symptoms, dryness of the trees which are in early tapping was another symptom which growers recognize a tree in diseased. In the early stage of the infection, application of management strategies are effective. According the reported incidences, the borer attack was also commonly observed as a secondary attack of the trees and which are beyond control.

Though the brown root disease shows a comparatively easy-to-diagnose signs and symptoms, the disease is not a very familiar disease to Sri Lankan rubber growers. It was noticed that the disease identification is lagging behind leading to further spread of the disease by accumulation of the inoculum in the plantations.

Higher incidence of brown root disease The majority of reported brown root disease incidences in this study were from rubber plantations established after clearing native forests. Moreover, the disease was frequently reported from the smallholders, where rubber is planted after leaving woody debris of the prior stand: either forest, rubber or some other crop species (Fig. 4). In all incidences, stumps of forest or some other tree species left behind at the time of land preparation were observed in contact with the firstly diseased plant of the current disease patch. 
M K R Silva et al.

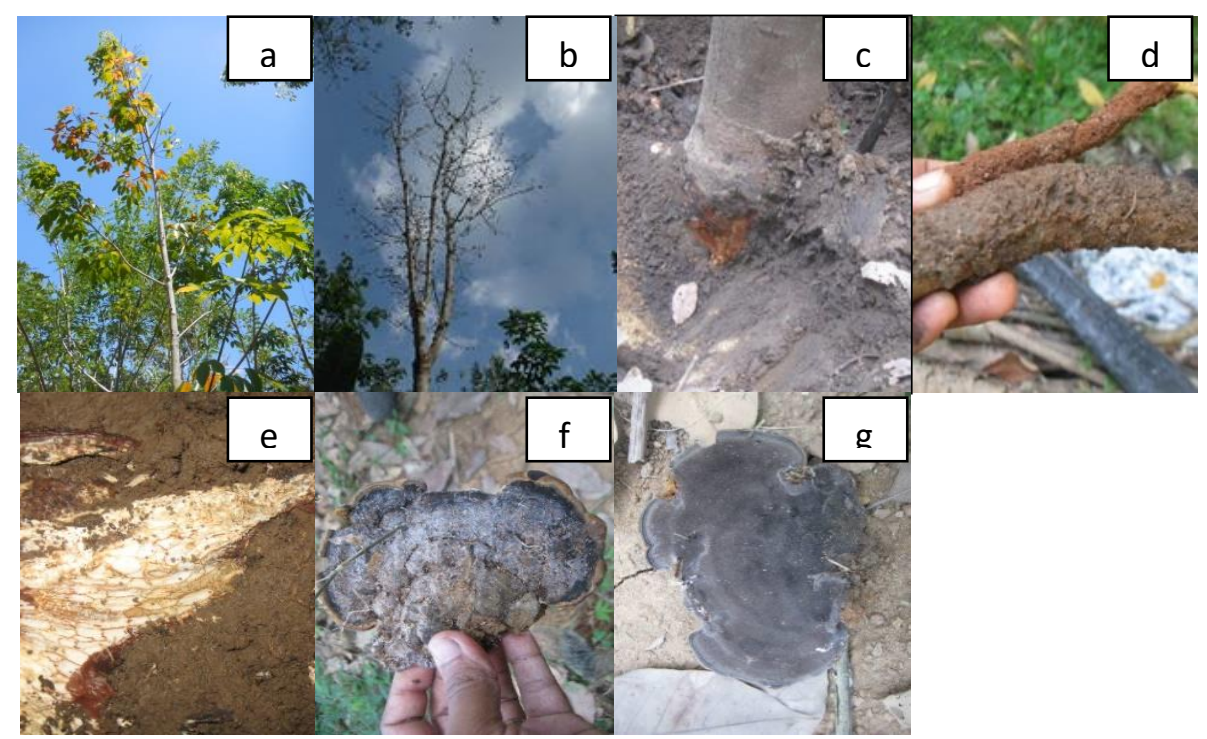

Fig. 3. Symptoms of the brown root disease of rubber plants a) yellowing and wilting of leaves - can not be seen; b) branch dieback; c) brown discoloration of the wood just beneath the bark; d) encrustation of sand and stones on the root surface; e) honeycombed wood; f) fruiting bodies (upper surface); g) fruiting bodies (lower surface)

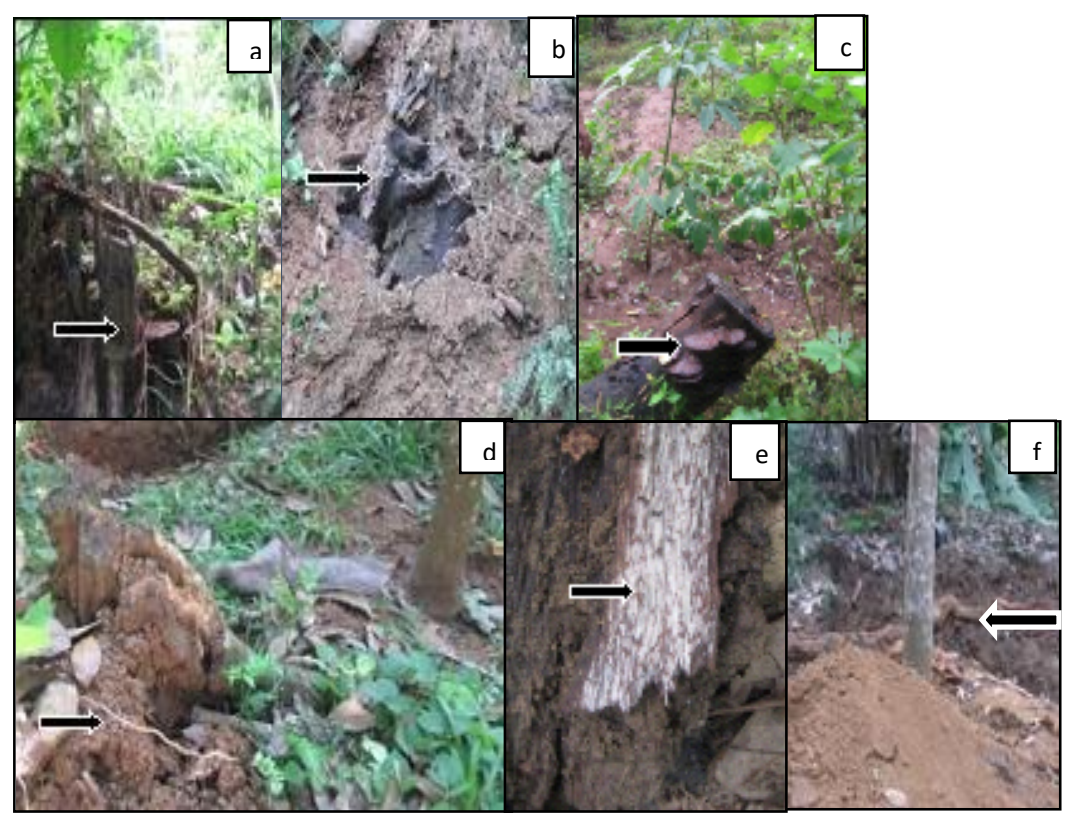

Fig. 4. Infected roots and stumps of forestry species: (a, b, c, d) fructifications on stumps (e) honey-comb appearance, (f) brown discoloration of the wood 
As per the observations, the presence of un-removed root pieces of the native tree species can be identified as one of the major factors favorable for the development of the brown root disease in those areas. According to the past records in Sri Lanka also the brown root disease causing fungus has been of common occurrence in the earlier days of rubber plantings. When rubber was inter planted in cocoa and tea fields. The rubber trees later got infected from the dead stumps remained after the removal of cocoa and tea by simply cutting off the bushes (Advisory Circular of RRISL, 1954).

When E. J. Corner described Fomes noxius (currently Phellinus noxius) as a new species in 1932, and it was usually found in cleared or disturbed areas. Since, the beginning of the $20^{\text {th }}$ century, many plantations of rubber, tea, cocoa, coffee, oil palm, and mahogany established on cleared forests sites had been infected or destroyed by $P$. noxius (Pegler et al., 1968). It can be expected that the inoculum is present in native tropical forests of Sri Lanka and new infection centers may have initiated when roots of the newly planted trees come in contact with infected stumps or other woody debris of cleared native forest. Further spread from the initial infection centers is through root contacts and $P$. noxius can persist in the roots and stumps of infected plants for more than ten years after the death of the host (Chang, 1996).

During the surveys carried out by Chang, Phellinus noxius occurred more frequently in fields with sandy soils, probably because sandy soils drain better and are less likely to become submerged for significant length of time, even during high rainfall (Chang, 1996). On the other hand, clay soils drain poorly; therefore these soils are more likely to be submerged, a situation that is detrimental to the survival of Phellinus noxius (Chang, 1996). The non-traditional areas are in the intermediate zone of the country, and is obvious that the soils are drier and less likely to become submerged for significant length of time. Therefore, the probability of brown root disease incidence is higher in such areas.

b) White root disease

With the similar signs and the symptoms to those observed in the traditional rubber-growing areas, 10 of the maladies were diagnosed as white root disease with the support with the cultural characteristics of the pathogen, Rigidoporus microporus. The presence of the dry soil conditions in these areas can be identified as the major reason for the reduction of the white root disease.

c) Corynespora leaf fall

Corynespora leaf fall, caused by Corynespora cassiicola was present on rubber in 15 incidences. It was confirmed by signs and symptoms culture characteristics and microscopic observations.

\section{Alternative hosts of the pathogens}

a) Brown root disease

However, the pathogen isolates could be obtained only from four alternative 
species, as some of the roots were too decayed. They were Careya arborea ('kahata'), Gmelina arborea ('eth demata'), decayed Mangifera indica (mango) and Artocarpus heterophyllus (jack). These isolates showed variation in their cultural characteristics (Fig. 1). The studies on the pathogenicity and the cross infectivity of the isolates among the tree species from which they were isolated and rubber are in progress.

Brown root disease has a very wide host range including, most of the economically-important plantation and other crop species such as, Camellia sinensis (tea), Coffea spp. (coffee), Artocarpus altilis (breadfruit), Cinnamomum spp. (cinnamon), Theobroma cacao (cocoa), Cocos nucifera (coconut), Garcinia mangostana (mangosteen), Citrus sp. (citrus), Mangifera indica (mango), Artocarpus heterophyllus (jack), Tectona grandis (teak) and Swietenia mahagoni (mahogany) (Chang 1996).

b) Corynespora leaf fall

As the above-mentioned cash crops are commonly intercropped with rubber in the study areas, the studies on the cross infectivity are in progress.

\section{Conclusion}

With the findings of the study, it can be concluded that, brown root disease was the malady with the highest incidence in the in non-traditional rubber-growing areas of Sri Lanka. Drier soil conditions, poor land preparation and association with the forest-associated tree species were the major reasons for higher incidence of this disease in the non-traditional rubber growing areas. The different isolates of Phellinus noxius showed variations in colony morphology. The coloration, density and the fluffiness in the culture figure showed variations and visible clusters could be obtained with all three characters. Corynespora leaf fall was found to be the foliar disease with the highest incidence. Cow pea (Vigna unguiculata), and Soy bean (Glycine max) were recorded to be two alternative hosts of Corynespora cassiicola. The importance of looking into the management of these maladies in non-traditional rubber-growing areas can be emphasized in order to have a sustainable rubber industry in the country.

\section{Acknowledgement}

Authors gratefully acknowledge the financial assistance provided by the Ministry of Plantation Industries for the disease identification in the nontraditional rubber-growing areas (Grant 23/1/15).

\section{References}

Advisory Circular No. 76 (Superseding Advisory Circular No. 63), Rubber Research Institute of Sri Lanka. 1967.

Ann, P J, Chang, T T and Ko, W H (2002). Phellinus noxius brown root rot of fruit and ornamental trees in Taiwan. Plant Dis. 86, 820-826.

CABI/EPPO (1997) Phellinus noxius. Distribution Maps of Plant Diseases No. 104. Wallingford, UK: CAB International.

Chang, T T (1996). Survival of Phellinus noxius in soil and in the roots of dead host plants. Phytopathology 86, 272-276. 
Chang, T T and Yang, W W (1998). Phellinus noxius in Taiwan: distribution, host plants and the $\mathrm{pH}$ and texture of rhizosphere soils of infected plants. Mycol. Res. 102, 1085-1088.

Corner, E J H (1932). The identification of the brown-root fungus. The Gdns. Bull. Straits Settlem. 5, 317-50.

Larsen, M J and Cobb-Poulle, L A (1990). Phellinus (Hymeno-chaetaceae). A Survey of the World Taxa. Synopsis Fungorum 3. Oslo, Norway: Fungiflora, 609 pp.

Murray, R K S (1930). Diseases of Rubber in Ceylon, Monogr. Rubber Res. Scheme, Ceylon, 38 pp.

Pegler, D N and Waterston, J M (1968). Phellinus noxius. CMI Descriptions of
Pathogenic Fungi and Bacteria, No.195. Commonwealth Mycological Institute, Kew, Surrey, England.

Petch, T (1911). The Physiology \& Diseases of Hevea brasiliensis the premier plantation rubber tree. Dulau and Co. Limited, London. 188-192.

Rencher, A C (2002). Methods of multivariate data analysis. $2^{\text {nd }}$ edition. John Wiley \& Sons, New York, USA.

Address for correspondence: Mrs M K R Silva, Research Officer, Plant Pathology \& Microbiology Dept., Rubber Research Institute of Sri Lanka, Dartonfield, Agalawatta, Sri Lanka,

e-mail:keshanis@rrisl.gov.lk 